\title{
Surface Grain Boundary Engineering of Alloy 600 for Improved \\ Resistance to Stress Corrosion Cracking
}

\author{
Abhishek Telang ${ }^{\mathrm{a}^{*}}$, Amrinder S. Gill ${ }^{\mathrm{b}}$, Deepthi Tammana ${ }^{\mathrm{a}}$, Xingshuo Wen ${ }^{\mathrm{a}}$, Mukul Kumar ${ }^{\mathrm{c}}, \mathrm{S}$. \\ Teysseyre $^{\mathrm{d}}$, Seetha R. Mannava ${ }^{\mathrm{a}}$, Dong Qian ${ }^{\mathrm{e}}$ and Vijay K. Vasudevan ${ }^{\mathrm{a}}$ \\ ${ }^{a}$ Department of Mechanical and Materials Engineering, University of Cincinnati, Cincinnati, OH \\ ${ }^{\mathrm{b}}$ AK Steel, Research Center, 705 Curtis Street, Middletown, OH \\ ${ }^{c}$ Lawrence Livermore National Laboratory, Livermore, CA \\ ${ }^{\mathrm{d}}$ Idaho National Laboratory, Idaho Falls, ID \\ ${ }^{\mathrm{e}}$ Department of Mechanical Engineering, University of Texas at Dallas, Richardson, TX
}

*Corresponding author information

\author{
Abhishek Telang \\ Address: Department of Mechanical and Materials Engineering \\ University of Cincinnati \\ 415 Rhodes Hall \\ 2901 Woodside Drive, \\ Cincinnati, OH, USA 45221-0012 \\ Email: telangam@mail.uc.edu \\ Phone: +1 513-556-3119 \\ Fax: +1 513-556-3773
}

\begin{abstract}
In this paper, we demonstrate a novel method for grain boundary engineering in Alloy 600 using iterative cycles of ultrasonic nanocrystal surface modification (UNSM) and strain annealing to modify the near surface microstructure $(\sim 250 \mu \mathrm{m})$ for improved stress corrosion cracking (SCC) resistance. These iterative cycles resulted in increased fraction of special grain boundaries whilst decreasing the connectivity of random grain boundaries in the altered near surface region. A disrupted random grain boundary network and a large fraction of low CSL boundaries $(\Sigma 3-\Sigma 27)$ reduced the propensity to sensitization. Slow strain rate tests in tetrathionate solutions at room temperature show that surface GBE lowered susceptibility to intergranular SCC. Detailed analysis of cracks using Electron Back-scattered Diffraction showed cracks arrested at J1(1-CSL) and J2 (2-CSL) type of triple junctions. The probability
\end{abstract}


for crack arrest, calculated using percolative models, was increased after surface GBE and explains the increase in resistance to SCC.

Keywords: EBSD, thermomechanical processing, nickel alloy, grain boundaries, residual stresses, twining

\section{Introduction}

Grain boundary engineering (GBE) has been demonstrated as a viable method for improving the resistance to creep[1,2], hydrogen embrittlement[3], fatigue[4,5], corrosion[68] and stress corrosion cracking[2,9-14] (SCC) in austenitic stainless steels (SS), Ni based alloys and superalloys. GBE involves increasing the frequency of coincident site lattice (CSL) grain boundaries whilst disrupting the random grain boundary network through thermo-mechanical processing routes. Low grain boundary energy, resistance to grain boundary sliding and intergranular degradation, less susceptibility to impurity or solute segregation are some reasons that contribute to the "special" nature of CSL boundaries.

Thermo-mechanical processing routes involving cold rolling or uniaxial tension/compression and subsequent annealing have been used to increase the frequency of CSL boundaries[6,15]. One approach involves a single cycle of pre-straining the material followed by annealing at comparatively lower temperature for a long time. A multi-cycle approach including steps of moderate strains (6-30\%) followed by relatively high temperature annealing for short times has also shown to increase the special grain boundary fraction[16,17]. In addition, the multi-cycle approach results in a disrupted random grain boundary network that correlates to improvements in fatigue, creep and corrosion resistance.

Detailed studies carried out by $\mathrm{Bi}$ et al. [18] have established that twin boundaries(especially coherent $\Sigma 3$ ) are more resistant to carbide precipitation and corrosion because the atomic structure is highly coherent as compared to high angle grain boundaries. In particular, $\Sigma 3$ and $\Sigma 9$ boundaries in grain boundary engineered SS304 have been observed 
to more resistant to sensitization while $\Sigma 27$ and other CSL boundaries were not really "special" in terms of their resistance to sensitization and thus intergranular stress corrosion cracking (IGSCC)[19]. Thus, it has been suggested that increased fraction of $\Sigma 3$ and $\Sigma 9$ boundaries would likely improve the corrosion and stress corrosion resistance.

Alloy 600 and austenitic stainless steels have been known to be susceptible to stress corrosion cracking (SCC) in polythionic acid environments[20-25]. Susceptibility to SCC at low temperature in tetrathionate and thiosulfate environments has been attributed to $\mathrm{Cr}$ depletion in the area surrounding the grain boundary. A reduction in $\mathrm{Cr}$ depletion by disrupting the random grain boundary network or increasing the fraction of special boundaries should decrease the susceptibility to sensitization and SCC $[6,18,19]$. While GBE has been studied extensively to improve resistance to intergranular cracking, surface GBE has not been explored to the same extent.

In this paper, we propose a novel approach to engineer the near surface region by using ultrasonic nanocrystalline surface modification (UNSM)/ultrasonic peening followed by annealing to increase the fraction of special boundaries. Further, we present and discuss the effect of this surface grain boundary engineered material on the SCC behaviour in tetrathionate solution. To the best of our knowledge, there are no studies investigating the effects of surface GBE on SCC behaviour of Alloy 600.

\section{Materials and Methods}

\subsection{Materials}

Alloy 600 plate ( $2 \mathrm{~mm}$ thickness) with chemical composition as shown in Table 1 was sectioned into $15 \mathrm{~mm} \times 15 \mathrm{~mm}$ coupons using a wire EDM. The as received material was in annealed condition with a grain size of $\sim 10 \mu \mathrm{m}$. UNSM is an advanced surface treatment that uses ultrasonic energy to strike a target (material surface) with a WC tip at a frequency of 20 $\mathrm{kHz}$ to induce strain in the near surface region of the material. 


\begin{tabular}{ccccccccccccc}
\hline $\mathbf{C}$ & $\mathbf{M n}$ & $\mathbf{S i}$ & $\mathbf{S}$ & $\mathbf{C r}$ & $\mathbf{F e}$ & $\mathbf{C o}$ & $\mathbf{C d}$ & $\mathbf{T i}$ & $\mathbf{C u}$ & $\mathbf{P}$ & $\mathbf{A l}$ & $\mathbf{N i}$ \\
\hline 0.08 & 0.16 & 0.18 & $\begin{array}{c}0.001 \\
\text { max. }\end{array}$ & 15.05 & 8.05 & 0.16 & 0.01 & 0.18 & 0.1 & $\begin{array}{c}0.001 \\
\text { max. }\end{array}$ & 0.08 & $\mathrm{Bal}$. \\
\hline
\end{tabular}

Table 1. Chemical composition of the Inconel Alloy 600 used in this study.

The amount of strain can be controlled by modifying the static and dynamic loads. A schematic of the UNSM process is shown in Figure 1. Static load $\left(\mathrm{P}_{\mathrm{st}}\right)$, amplitude of ultrasonic vibration, scan speed and overlap ratio can be controlled during processing. Details of UNSM have been reported elsewhere in literature [26,27]. For grain boundary engineering, coupons were peened using a LM20 UNSM system (DesignMecha) and subsequently annealed in a lab furnace for 10 minutes at $950{ }^{\circ} \mathrm{C}$ or $1000{ }^{\circ} \mathrm{C}$, then water quenched (WQ). Processing details for surface GBE are listed in Table 2. AR and ARGBE conditions have been grouped together as Set 1 while SA and SAGBE are categorized as Set 2. The static load was $20 \mathrm{~N}$ and the amplitude of ultrasonic vibration was $8 \mu \mathrm{m}$. A scan speed of 3000 $\mathrm{mm} / \mathrm{minute}$ and overlap interval of $30 \mu \mathrm{m}$ was used for UNSM processing in this study.

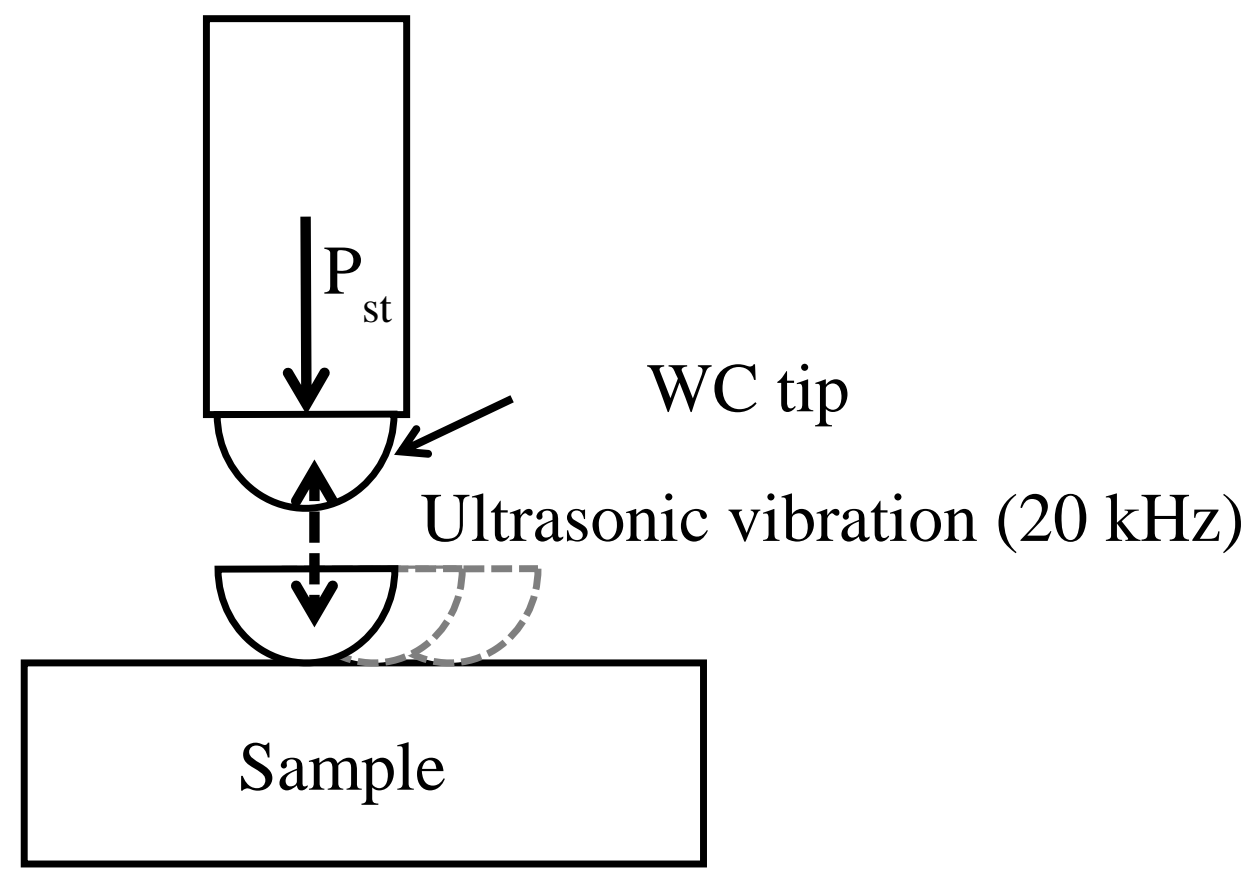

Figure 1. Schematic of the ultrasonic peening setup

After GBE treatments, samples were sectioned and cross sections were mounted in a conducting epoxy. For EBSD, each sample was ground to 1200 grit, electropolished in 
87.5:12.5 vol.\% $\mathrm{CH}_{3} \mathrm{OH}: \mathrm{H}_{2} \mathrm{SO}_{4}$ solution at $24 \mathrm{~V}, 15 \mathrm{~s}$ and finally polished with $0.05 \mu \mathrm{m}$ colloidal silica suspension. EBSD orientation mapping was performed in a FEI XL-30 SEM with step size of $2 \mu \mathrm{m}$ at $30 \mathrm{kV}$. OIM scans were analysed with the TSL OIM Analysis (version 7.1) package to calculate grain boundary character distribution (GBCD), grain size, boundary fractions and triple junction fractions. CSL grain boundaries were categorized according to Brandon criterion of $\Delta \theta \leq 15^{\circ} \Sigma^{-1 / 2}$ [28]. Boundaries with $3<\Sigma<29$ were considered to be CSL boundaries whereas boundaries with $\Sigma>29$ were considered random high angle boundaries (HABs) and $\Sigma=1$ as low angle boundaries (LABs). For triple junction analysis, only $\Sigma 3, \Sigma 9$ and $\Sigma 27$ were considered as CSL boundaries.

\begin{tabular}{cc}
\hline Designation & Detail \\
\hline AR & As received \\
\hline ARGBE & $\mathrm{AR}+3$ cycles of (UNSM + annealing at $\left.950^{\circ} \mathrm{C}, 10 \mathrm{~min}, \mathrm{WQ}\right)$ \\
\hline $\mathrm{SA}$ & $\mathrm{AR}+$ Solution annealing at $1050^{\circ} \mathrm{C}, 10 \mathrm{~min}, \mathrm{WQ}$ \\
\hline SAGBE & $\mathrm{SA}+3$ cycles of $\left(\mathrm{UNSM}+\right.$ annealing at $\left.1000^{\circ} \mathrm{C}, 10 \mathrm{~min}, \mathrm{WQ}\right)$ \\
\hline
\end{tabular}

Table 2. Designation and corresponding details of processing used in this study.

\subsection{Residual stress and FWHM}

Residual stresses were measured using $\sin ^{2} \psi$ technique with a Proto LXRD system, $\mathrm{MnK} \alpha$ radiation and (311) peak of the austenite phase. To measure residual stress through depth, coupons were electropolished using 87.5:12.5 vol.\% $\mathrm{CH}_{3} \mathrm{OH}: \mathrm{H}_{2} \mathrm{SO}_{4}$ solution to remove 10-50 $\mu \mathrm{m}$ layers. Full width at half maximum (FWHM) data was also recorded for each depth. 


\subsection{Double loop electrochemical potentiokinetic reactivation (DLEPR) tests}

Baseline and grain boundary engineered samples were given a sensitization treatment at $650^{\circ} \mathrm{C}, 2 \mathrm{~h}$ (water quenched) to induce precipitation of carbides. These samples were mechanically ground to 1200 grit, wet polished with $1 \mu \mathrm{m}$ diamond suspension and finished with $0.05 \mu \mathrm{m}$ colloidal silica suspension DLEPR tests were performed in accordance with ASTM G108-94 in a solution composed of $0.01 \mathrm{M} \mathrm{H}_{2} \mathrm{SO}_{4}+20$ ppm KSCN using a Gamry Potentiostat (Reference 600). Samples were kept immersed in the test solution for 1 hour at open circuit potential before the start of each test. The scan rate was set at $0.5 \mathrm{mV} / \mathrm{s}$ for activation and reactivation loop and the sample size was $1 \mathrm{~cm}^{2}$. Freshly prepared solution was de-aerated with high purity Ar gas before and during each test. All tests were performed at room temperature.

The following procedure was used to quantify sensitization in the annealed and GBE material after sensitization[29]. The degree of sensitization is reported as DL-EPR value (designated as $\mathrm{R}$ in $\%$ ) which is the ratio of the current density in reactivation loop to that in the activation loop times 100 .

$$
R=\frac{I r}{I a} \times 100
$$

The DL-EPR value obtained is normalized with various parameters like grain boundary area (GBA), grain size, mean lineal intercept length (MIL). It should be noted that twins have been excluded from grain size analysis. The DL-EPR value of a given alloy condition (with ASTM grain size number of G') is normalized with the grain size (with ASTM grain size number of $\mathrm{G}$ ) of the as-received material (SA) and is given by:

$$
R^{\prime}=R \times \sqrt{2^{G^{\prime}-G}}
$$

The DL-EPR values were also normalized with grain boundary area $\left(S_{v}\right.$, expressed in $\left.\mathrm{mm}^{2} / \mathrm{mm}^{3}\right)$ : 


$$
R_{G B A}=\frac{R}{S_{v}}
$$

The DL-EPR values were also normalized with mean intercept length (designated by $l$ ):

$$
R_{M I L}=\frac{R}{l}
$$

Here $l$ is expressed in $\mu \mathrm{m}$. The grain boundary area and mean lineal intercept length can be obtained from the number of intercepts per unit length $\left(\mathrm{N}_{\mathrm{L}}\right)$ of the test line [30] . The $\mathrm{N}_{\mathrm{L}}$ can be calculated from the following equation [30]:

$$
G=-3.2877+6.6439 \log _{10} N_{L}
$$

where $\mathrm{N}_{\mathrm{L}}$ is a number of intercepts per unit length and $\mathrm{G}$ is the ASTM grain size number. The mean lineal intercept $(l)$ and the GBA, $S_{v}$, are given by [30]:

$$
l=\frac{1}{N_{L}}, S_{v}=2 N_{L}
$$

\subsection{Slow strain rate tests (SSRT)}

GBE samples were prepared by UNSM treating 2 sides a $2 \mathrm{~mm}$ thick Alloy 600 (in AR and SA conditions), then strain annealing. This was repeated 3 times with the same process parameters as listed in Table 2. All samples were then given a sensitization treatment at $650{ }^{\circ} \mathrm{C}, 2 \mathrm{~h}$. Flat samples with gage length of $6 \mathrm{~mm}$ were fabricated using wire EDM, polished to 1200 grit, degreased with acetone, dried and immersed in the test solution for 1 hour prior to straining. Samples were strained at rate of $2 \times 10^{-6} \mathrm{~s}^{-1}$ for all tests. Slow strain rate tests (SSRT) were performed with a SSRT system (Cortest Inc. Willoughby, Ohio) driven by a servo motor and fitted with a custom built environmental chamber. Load and displacement values were recorded periodically and samples were strained to failure. Some SSRTs were interrupted after 10\% nominal strain and held at constant load for 24 hours or failure. Test solutions $(0.001-0.01 \mathrm{M})$ were prepared using reagent grade $\mathrm{Na}_{2} \mathrm{~S}_{4} \mathrm{O}_{6}$ sodium 
tetrathionate (Sigma-Aldrich) and distilled water. For certain tests, solution $\mathrm{pH}$ was adjusted with the appropriate amount of dilute $\mathrm{H}_{2} \mathrm{SO}_{4}$.

\section{Results}

\subsection{Residual stresses and FWHM}

Residual stresses after ultrasonic peening were measured at different depths and plotted in Figure 2(a). The in-plane residual stresses are of the order of $-1200 \mathrm{MPa}$ and $-700 \mathrm{MPa}$ along (phi 90) and perpendicular (phi 0) to the scanning direction respectively. Differences in residual stresses in the 2 directions are attributed to the processing parameters and have been reported previously [26,31]. In addition, FWHM data plotted in Figure 2(b) shows high level of plastic strain at the surface which decreases gradually through depth. Significant peak broadening is observed at the surface and FWHM decreases to $\sim 50 \%$ as represented by the normalized FWHM scale (secondary axis). The magnitude of residual stresses and FWHM indicate a high level of strain and plastic deformation that varies through depth. Significant strain and plastic deformation is observed within the first 250-300 microns after ultrasonic peening and hence the near surface region is likely to show strain induced microstructural changes after annealing. 


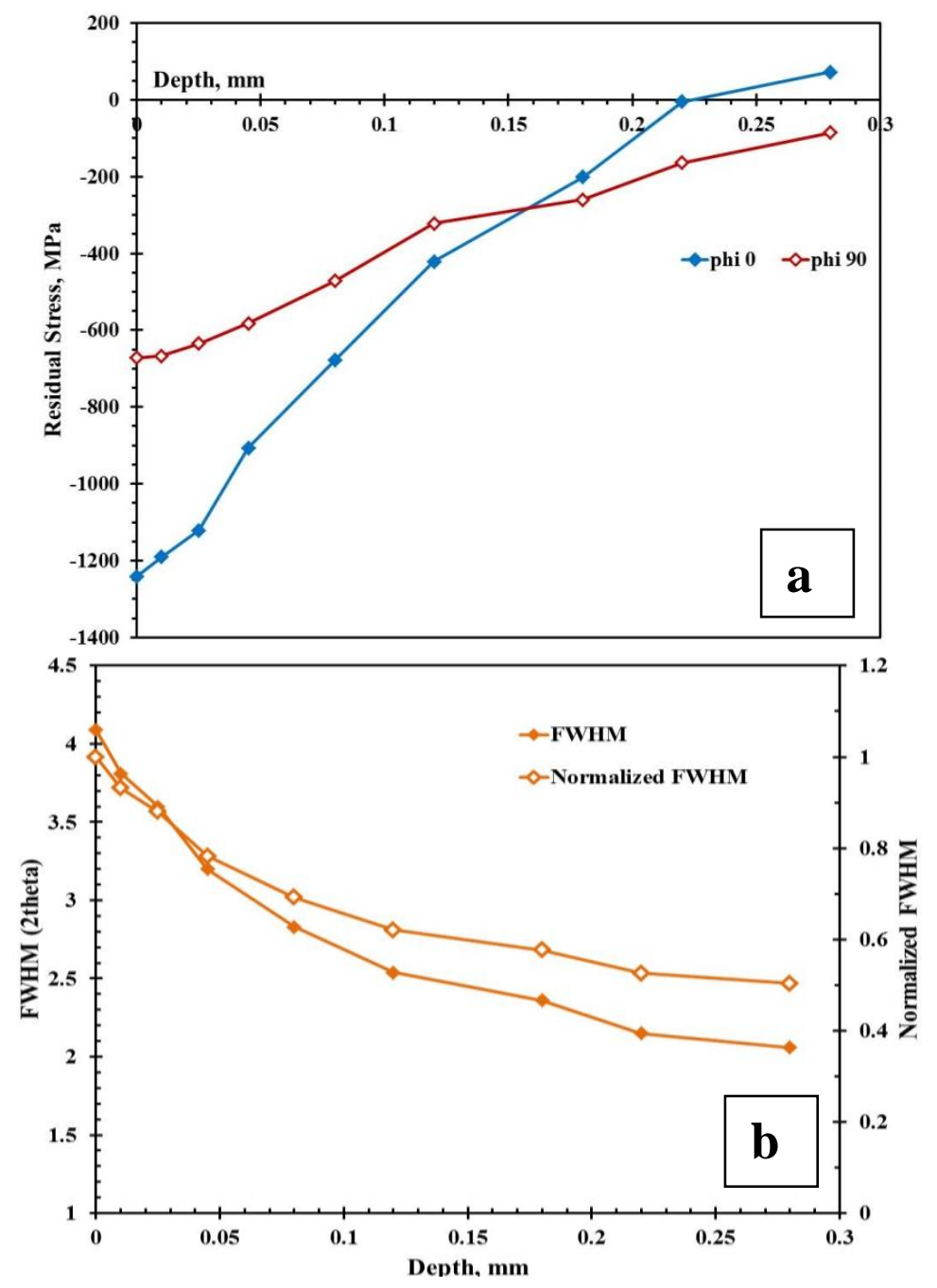

Figure 2. (a) Residual stresses and (b) FWHM after UNSM in Alloy 600.

\subsection{Microstructure}

In this study, GBE treatment was applied to 2 sets of Alloy 600 with different initial starting conditions (AR and SA). An experimental matrix with different UNSM parameters and annealing temperatures was used to observe changes in grain boundary character distribution (GBCD) in the near surface region $(\sim 250 \mu \mathrm{m})$. GBCD statistics obtained were compared with those from thermo-mechanical processing routes in the FCC materials including Alloy 600 that have been reported previously[6,7,16,19].

Grain boundary maps from the AR and SA condition are shown in Figure 3 (a) and (c) respectively. The microstructure obtained as a result of repeating the (peening + annealing) 
cycle for 3 times, designated as ARGBE and SAGBE are shown in Figure 3 (b) and (d) respectively. All orientation maps were obtained from $200-250 \mu \mathrm{m}$ perpendicular to the peened side. For analysis of triple junctions, only $\Sigma 3, \Sigma 9$ and $\Sigma 27$ have been considered. Triple junctions with no CSL boundaries, 1 CSL boundary, 2 CSL and 3 CSL boundaries have been classified as $\mathrm{J} 0, \mathrm{~J} 1, \mathrm{~J} 2$ and $\mathrm{J} 3$ respectively.

Grain boundary fractions (length), grain size and triple junction fractions for the 2 sets have been summarized in Figures 4 (a-c). In set 1(AR), the HAB fraction (length) decreased from $58 \%$ to $28 \%$ in ARGBE while the CSL fraction increased from $36 \%$ to $66 \%$. The fraction of $\Sigma 3$ boundaries increased from $27 \%$ in the AR condition to $53 \%$ after GBE. More importantly, fractions of $\Sigma 9+\Sigma 27$ increased from $3.4 \%$ (AR) to $10.2 \%$ (ARGBE). An increase in the $\Sigma 9, \Sigma 27$ fractions has been attributed to the $\Sigma 3$ regeneration model proposed by Randle et al. [32,33]. In addition, triple junction fractions extracted from the orientation maps show a sharp drop in fraction of $\mathrm{J} 0$ type from $48 \%$ to $10 \%$. $\mathrm{J} 2$ and $\mathrm{J} 3$ fractions increase from $3 \%(\mathrm{AR})$ to $12 \%(\mathrm{ARGBE})$ and $4 \%(\mathrm{AR})$ to $29 \%(\mathrm{ARGBE})$ respectively. These changes in triple junction fractions are consistent with the GBE model proposed by Kumar et al. $[16,34]$. 

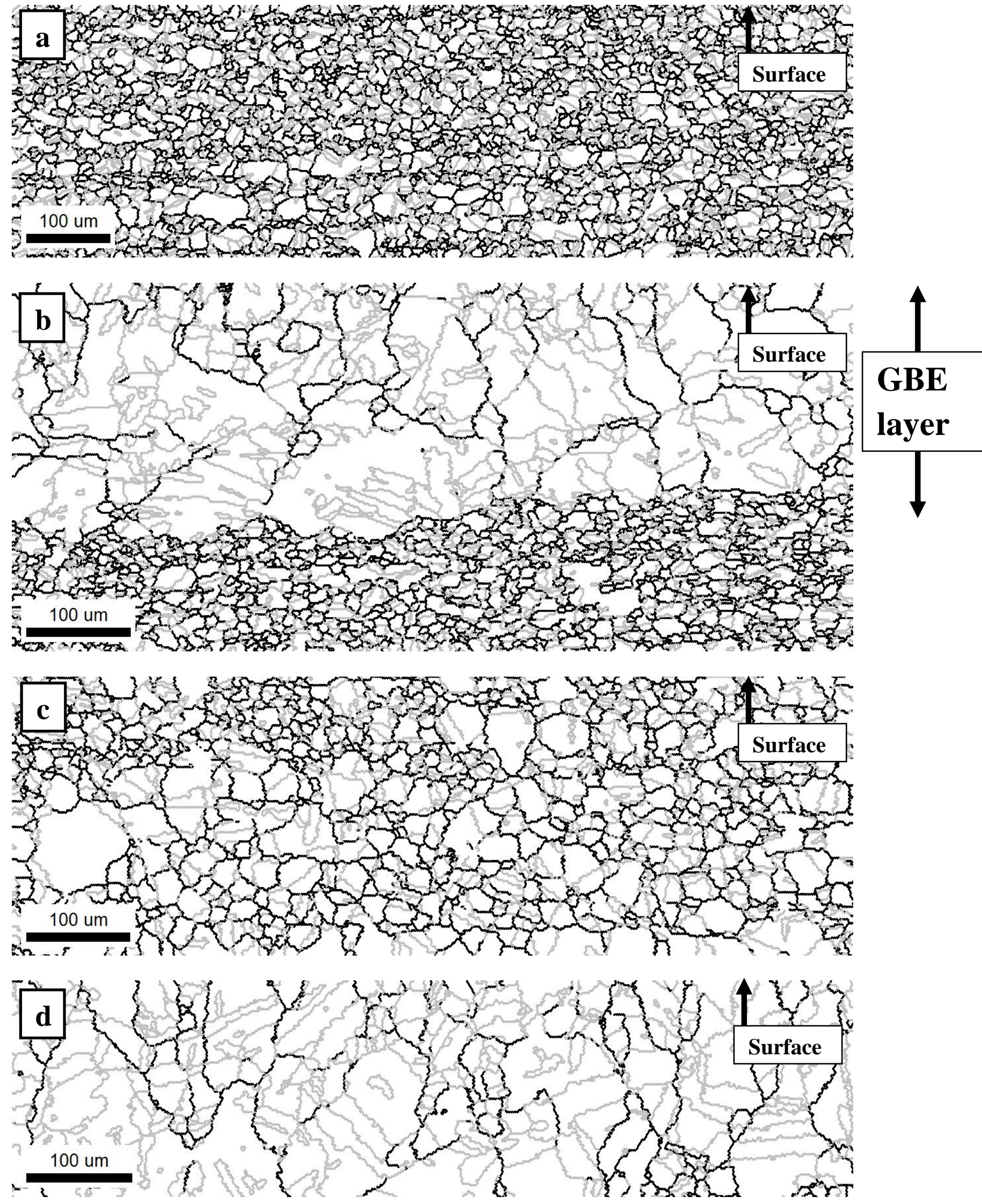

Figure 3. EBSD orientation maps showing the microstructure in the cross-section for (a) AR (b) ARGBE, (c) SA and (d) SAGBE conditions. Black lines denote random high angle grain boundaries and grey lines denote CSL boundaries $(\Sigma \leq 27)$. 

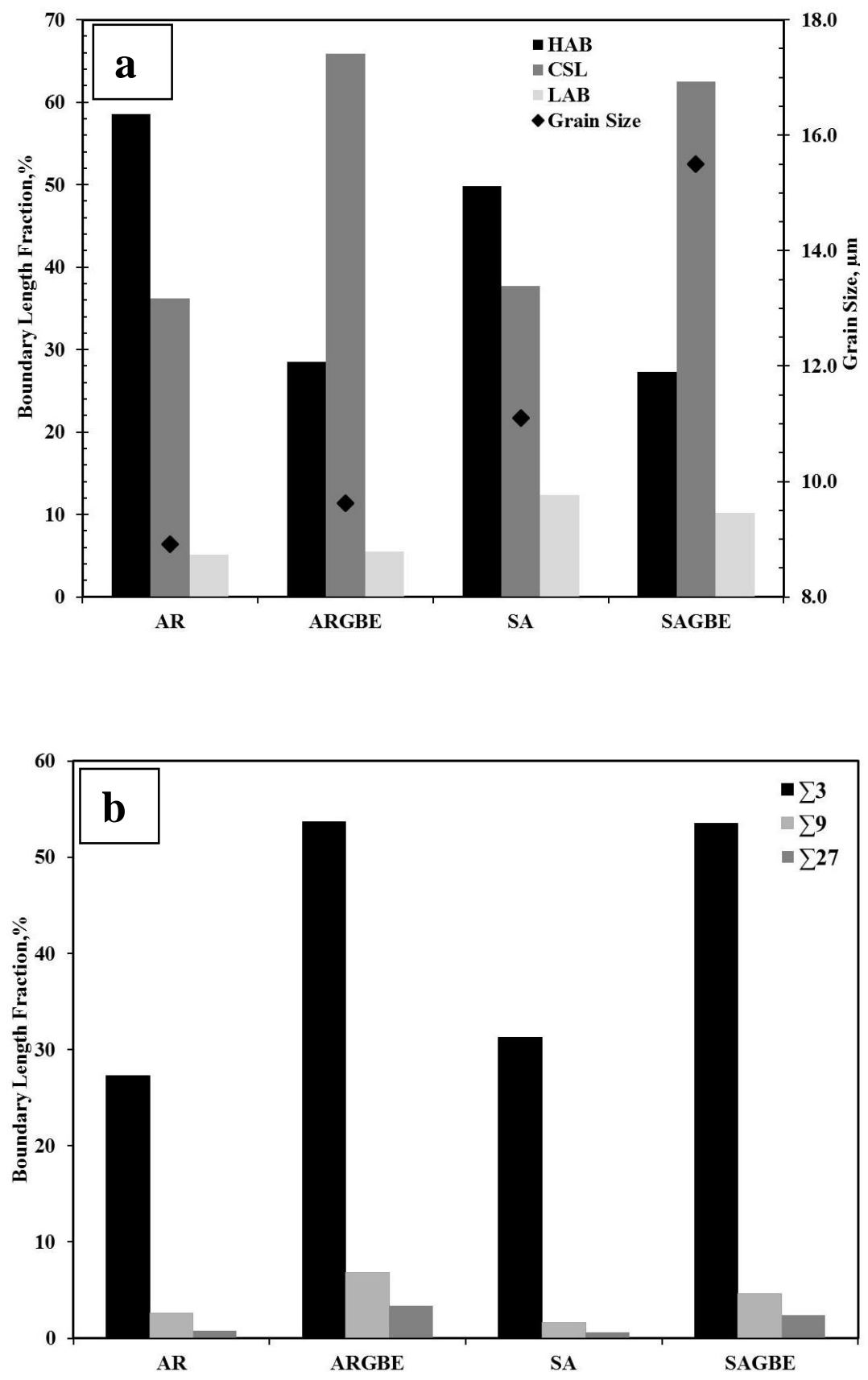

In set 2, the HAB fraction (length) decreased from $49 \%$ to 27\% in SAGBE while the CSL fraction increased from $37 \%$ to $63 \%$. The fraction of $\Sigma 3$ boundaries increased from $31 \%$ in the SA condition to $54 \%$ after GBE. $\Sigma 9+\Sigma 27$ fractions increased from $2.2 \%$ (SA) to $7 \%$ (SAGBE). Similarly, J0 fraction dropped from $43 \%$ to $12 \%$ while $\mathrm{J} 2$ and $\mathrm{J} 3$ fractions increased from 3\% (SA) to $11 \%$ (SAGBE) and 3\% (SA) to $21 \%$ (SAGBE) respectively. 
Grain size increased modestly from $9 \mu \mathrm{m}$ to $\sim 12 \mu \mathrm{m}$ in set 1 and from $11 \mu \mathrm{m}$ to 15 $\mu \mathrm{m}$ in set 2 after grain boundary engineering.

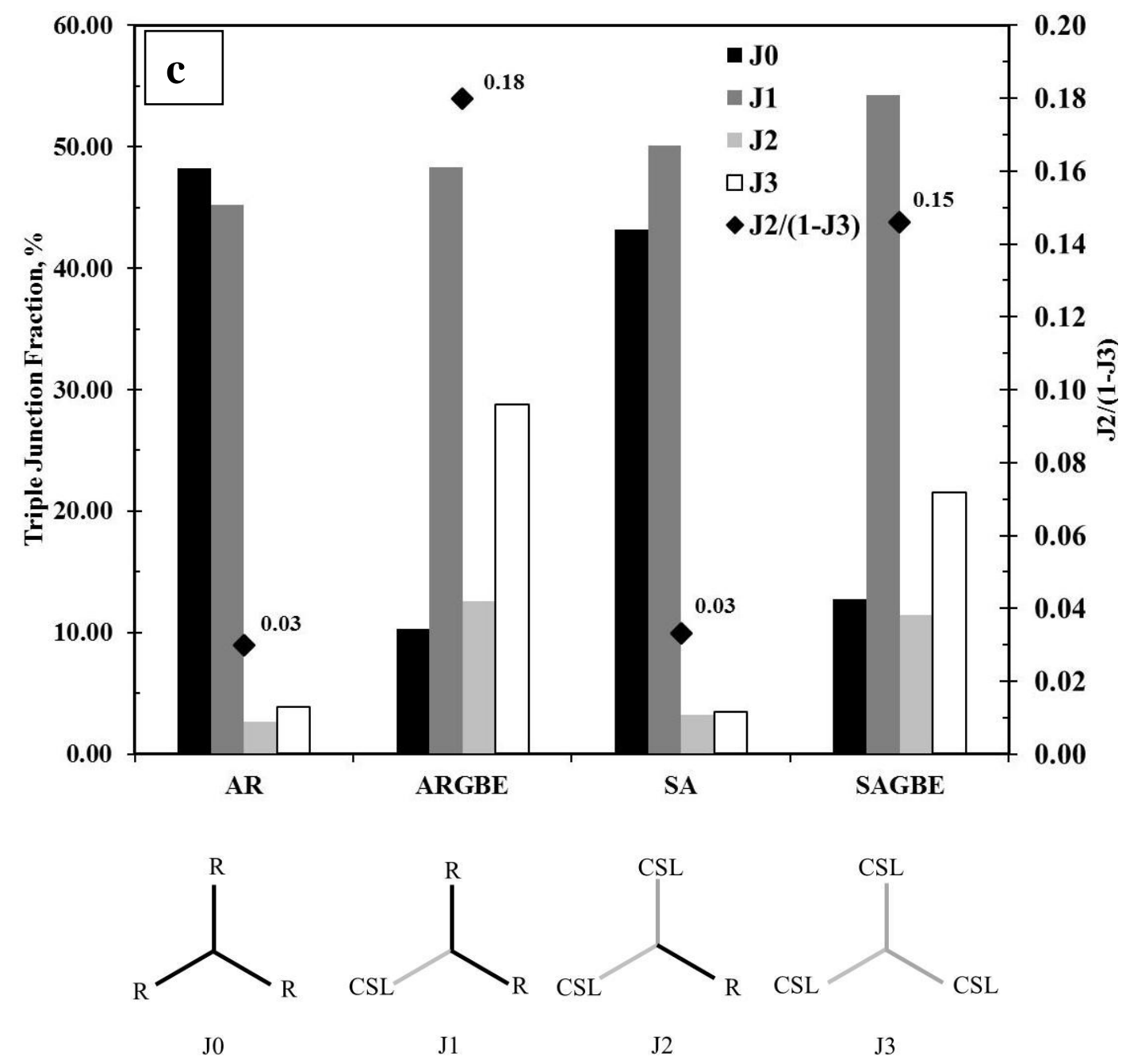

Figure 4. (a) Grain boundary character distribution and grain size, (b) CSL boundary fraction and (c) triple junction fraction for each processing condition. Note that boundary and triple junction fractions are from $\sim 200 \mu \mathrm{m}$ from the top surface.

\subsection{Sensitization}

After a sensitization treatment of $650^{\circ} \mathrm{C}, 2 \mathrm{~h}$ (water quenched) and DLEPR tests were used to quantify the degree of sensitization for each condition. The as-received material was in annealed condition with a relatively finer grain size $(\sim 9 \mu \mathrm{m})$. In case of the SA condition, the larger grain size and more carbon in the solid solution contributed to the increase in 
susceptibility to sensitization. DOS values increased from 0.56 to 2.58 after the annealing treatment prior to sensitization as summarized in Table 3.

\begin{tabular}{cccccc}
\hline Sample & CSL fraction, $\%$ & $\mathbf{R}$ & $\mathbf{R}^{\prime}$ & $\mathbf{R}_{\text {GBA }}$ & $\mathbf{R}_{\text {MIL }}$ \\
\hline AR & 36.2 & 0.56 & 0.5593 & 0.0053 & 0.0299 \\
ARGBE & 65.9 & 0.06 & 0.0217 & 0.0015 & 0.0012 \\
SA & 37.7 & 2.58 & 2.5766 & 0.0323 & 0.1032 \\
SAGBE & 62.5 & 0.04 & 0.0285 & 0.0006 & 0.0011 \\
\hline
\end{tabular}

Table 3. CSL fraction and corresponding degree of sensitization (R) values for each processing condition.
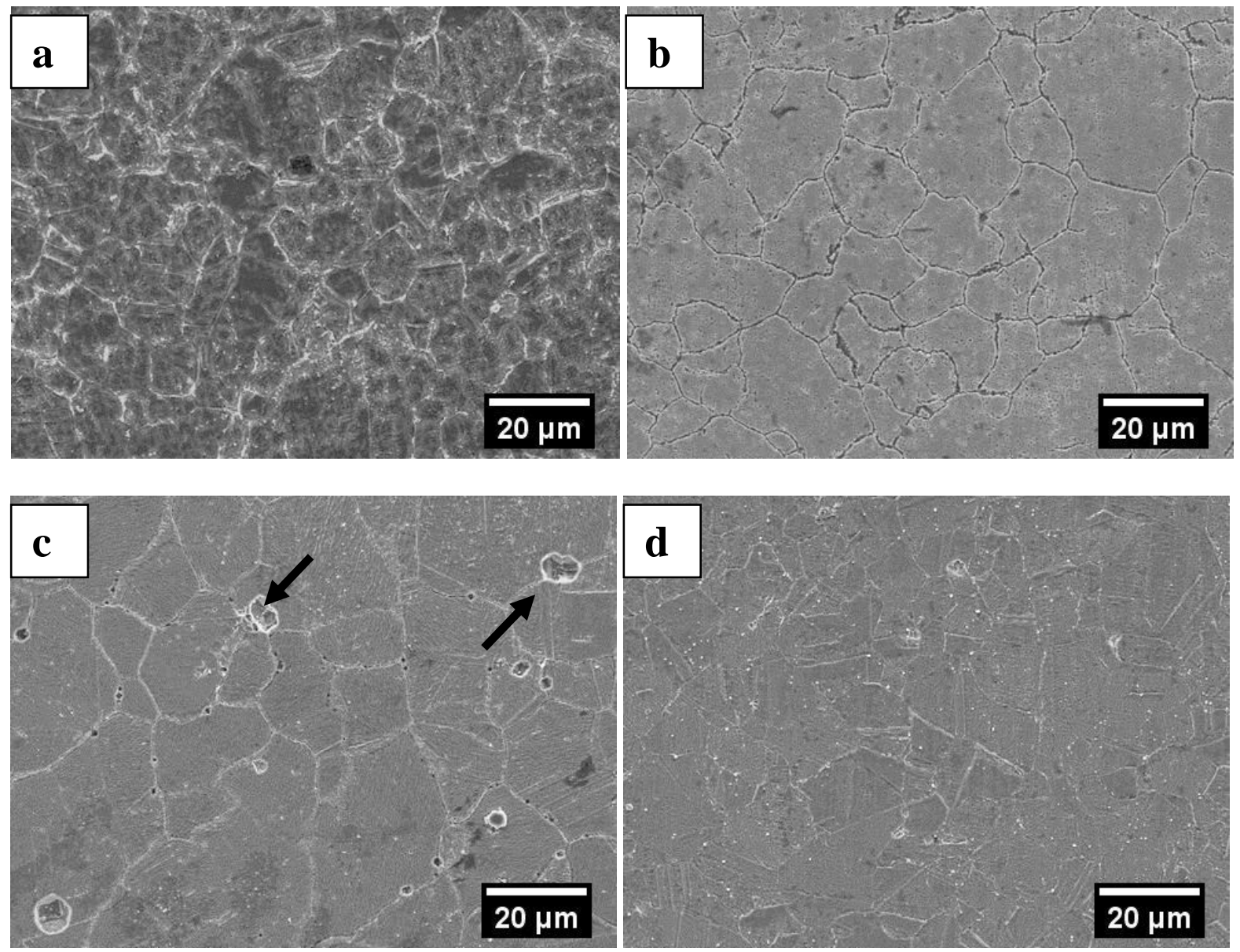

Figure 5. SEM images showing microstructure after DLEPR test for (a) AR, (b) ARGBE, (c) SA and (d) SAGBE conditions. Samples were given a sensitization treatment for 2 hours at $650^{\circ} \mathrm{C}$ to induce sensitization prior to DLEPR tests.

More importantly, DOS values (R) for ARGBE was $0.06 \%$ as compared with $0.56 \%$ for the AR condition (Set 1). Similarly, DOS value was much lower $(0.04 \%)$ for SAGBE condition 
as compared with (2.58\%) for the SA condition. Micrographs obtained after DLEPR tests for each condition are shown in Figure 5. Note that DLEPR tests were performed on the surface (within $50 \mu \mathrm{m}$ from peened surface) and after sensitization. DOS values normalized by grain size, $\left(\mathrm{R}^{\prime}\right)$, grain boundary area $\left(\mathrm{R}_{\mathrm{GBA}}\right)$ and mean intercept length $\left(\mathrm{R}_{\mathrm{MIL}}\right)$ also show similar trends. The dramatic reduction in DOS has been correlated with increased CSL fractions after thermo-mechanical processing $[6,19,29]$. The decrease in the DOS indicates higher SCC resistance and results from SSRTs in tetrathionate solution are presented in the next section.

\subsection{Slow strain rate tests}

The increase in the CSL fractions and $\mathrm{J} 2 /(1-\mathrm{J} 3)$ fractions are indicative of the disruption in the grain boundary network after grain boundary engineering. A decrease in DOS (calculated from DLEPR tests) implies less $\mathrm{Cr}$ depletion after grain boundary engineering. The lower DOS can improve the SCC resistance of Alloy 600 in thiosulfate and tetrathionate solutions. Hence, SSR tests were performed to observe and quantify the decreased susceptibility to IGSCC after GBE. Stress-strain curves obtained from SSR tests in tetrathionate solution are as shown in Figure 6. Tests were performed at the same strain rate and in the same environment show a difference in SCC behavior. For Set 1, the elongation to failure was $85 \%$ for $\mathrm{ARGBE}$ as compared to $68 \%$ for $\mathrm{AR}$ condition in $0.01 \mathrm{M} \mathrm{Na}_{2} \mathrm{~S}_{4} \mathrm{O}_{6}$ solution. However, both AR and ARGBE showed ductile mode of a failure with no intergranular cracking. DOS values obtained from DLEPR tests had indicated that both the AR and ARGBE conditions were not severely sensitized so a more aggressive environment was used during SSRT. In acidified $0.001 \mathrm{M} \mathrm{Na}_{2} \mathrm{~S}_{4} \mathrm{O}_{6}$ solution with $\mathrm{pH} 3$ ( $\mathrm{pH}$ reduced by addition of dilute $\mathrm{H}_{2} \mathrm{SO}_{4}$ ), the strain to failure for AR was $26 \%$ as compared to $\sim 50 \%$ for ARGBE condition. Addition of sulfuric acid to reduce the $\mathrm{pH}$ of the solution has been shown to be more aggressive towards austenitic stainless steels and Ni alloys [22,35]. 
In case of Set 2, the elongation to failure was only $15 \%$ for SA condition while SAGBE condition was about $26 \%$ in $0.01 \mathrm{M} \mathrm{Na}_{2} \mathrm{~S}_{4} \mathrm{O}_{6}$ solution. Analysis of the fracture surface after tests showed mixed mode of failure for SAGBE condition while SA condition showed $100 \%$ intergranular cracking. DLEPR tests conducted previously had indicated higher sensitization as compared to the as received material. The low elongation to failure in the SA condition and intergranular mode of failure indicates that the material was more severely sensitized as compared to the AR condition. Secondary cracks from the gage sections of samples were analyzed in greater detail and discussed in the next section.

To quantify the effect of LSP on the susceptibility to IGSCC in tetrathionate solutions, the following equation proposed by Abe et al. [36] was used to calculate the SCC index ( $\left.\mathrm{I}_{\mathrm{SCC}}\right)$,

$$
I_{S C C}=\left[\frac{1+e_{n}}{1+e_{n}^{S C C}}\right] \times\left[\frac{P_{n}}{P_{n}^{S C C}}-1\right]
$$

where $e_{n}$ and $e_{n}{ }^{S C C}$ are strains at the maximum load for load-elongation plot in air and environment respectively. $P_{n}$ and $P_{n} S C C$ are the maximum loads for load-elongation plot in air and environment respectively. Table 4 summarizes the results from SSR tests in $0.01 \mathrm{M}$ $\mathrm{Na}_{2} \mathrm{~S}_{4} \mathrm{O}_{6}$ solution. For Set 1 , the $\mathrm{I}_{\mathrm{SCC}}$ drops from 0.6 to 0.13 after GBE in acidified $0.001 \mathrm{M}$ $\mathrm{Na}_{2} \mathrm{~S}_{4} \mathrm{O}_{6}$ solution( $\mathrm{pH}=3$ ). In case of Set 2 , GBE reduces the $\mathrm{I}_{\mathrm{SCC}}$ to 1.21 as compared to 2.17 for the SA condition.

Kikuchi patterns degrade due to strain and SAGBE samples had undergone close to $30 \%$ strain before failure during the SSR test in $0.01 \mathrm{M} \mathrm{Na}_{2} \mathrm{~S}_{4} \mathrm{O}_{6}$ solution. Further, SA and SAGBE samples were strained to $10 \%$ (nominal strain) and held for 24 hours (or failure) at the same stress level $( \pm 5 \mathrm{~N})$. The SA sample failed in 8 hours after $10 \%$ strain while the SAGBE sample did not fail in 24 hours (after 10\% strain) and the test was terminated. Cracks were observed on the gage section of both samples and were analyzed in greater detail. EBSD 
orientation maps from regiosn including crack tips and their analysis are presented in the next section.

\begin{tabular}{ccccc}
\hline Specimen & \%Elongation & Degree of Sensitization,\% & I $_{\text {Scc }}$ & Mode of failure \\
\hline AR & 63.75 & 0.56 & & Ductile \\
ARGBE & 83.21 & 0.06 & & Ductile \\
AR_PH3 & 26.28 & 0.56 & 0.60 & IGSCC \\
ARGBE_PH3 & 50.03 & 0.06 & 0.13 & IGSCC \\
SA & 16.19 & 2.5 & 2.17 & IGSCC \\
SAGBE & 25.33 & 0.04 & 1.21 & IGSCC \\
\hline
\end{tabular}

Table 4. Summary of Stress-strain data from SSRT for each processing condition. All tests were performed at room temperature Strain rate was $2 \times 10^{-6} / \mathrm{s}$.

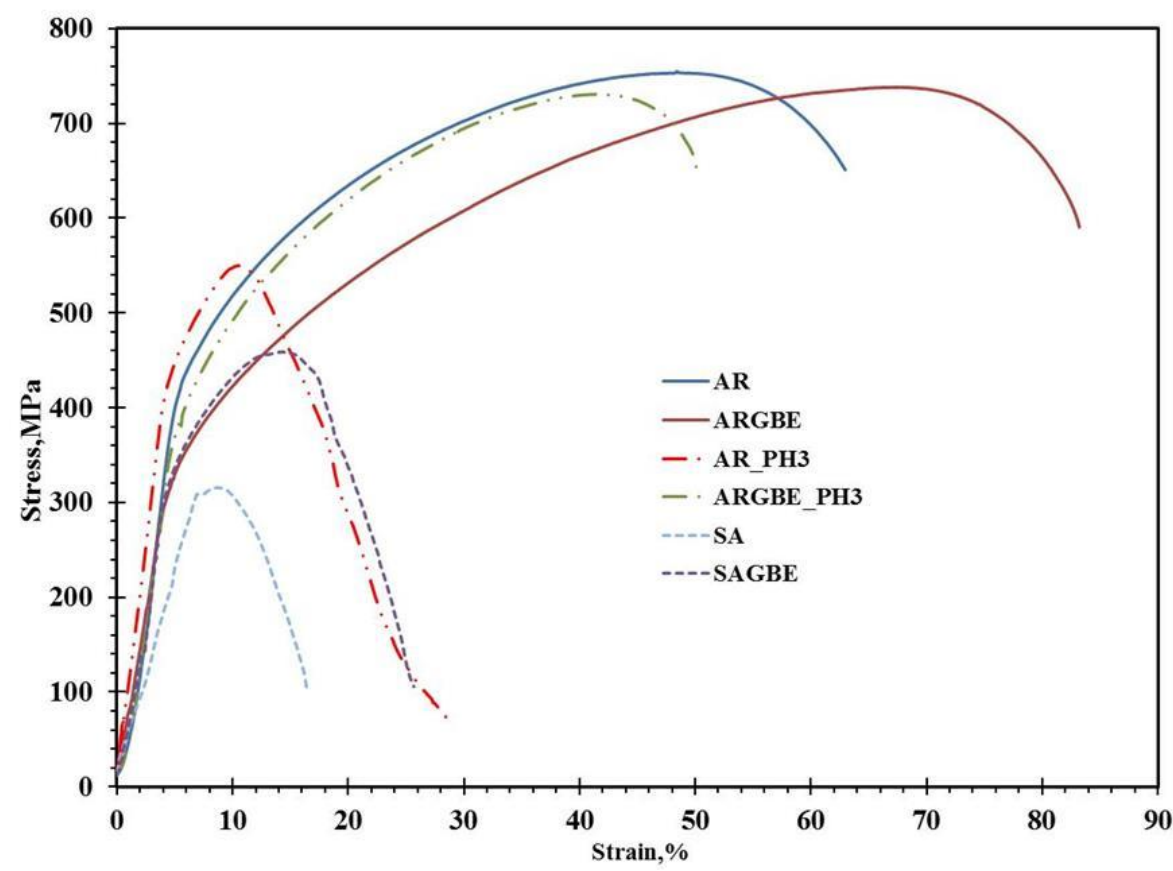

Figure 6. Stress-strain curves for baseline and grain boundary engineered samples (after sensitization at $650^{\circ} \mathrm{C}, 2 \mathrm{~h}$, water quenched) in $0.01 \mathrm{M} \mathrm{Na} \mathrm{S}_{4} \mathrm{O}_{6}$ solution. Strain rate: $2 \times 10^{-6} / \mathrm{s}$. For tests designated $\mathrm{PH3}$, dilute $\mathrm{H}_{2} \mathrm{SO}_{4}$ was added to $0.001 \mathrm{M} \mathrm{Na}_{2} \mathrm{~S}_{4} \mathrm{O}_{6}$ solution to reduce $\mathrm{pH}$ to 3 .

\subsection{SCC behavior}

Detailed analysis of the fracture surface and secondary cracks from the gage section after SSR tests shows intergranular nature of cracking. EBSD orientation maps from areas including cracked boundaries were used to assess the cracking behavior. In case of SA 
condition, elongation to failure was $16 \%$ and the mode of failure was intergranular in nature as shown in Figure 7 (b). A number of secondary cracks were observed in the gage section as shown in Figure 7 (a, c). Image quality (IQ) map overlaid with grain boundaries in Figure 7(d) shows the cracks following an intergranular path.

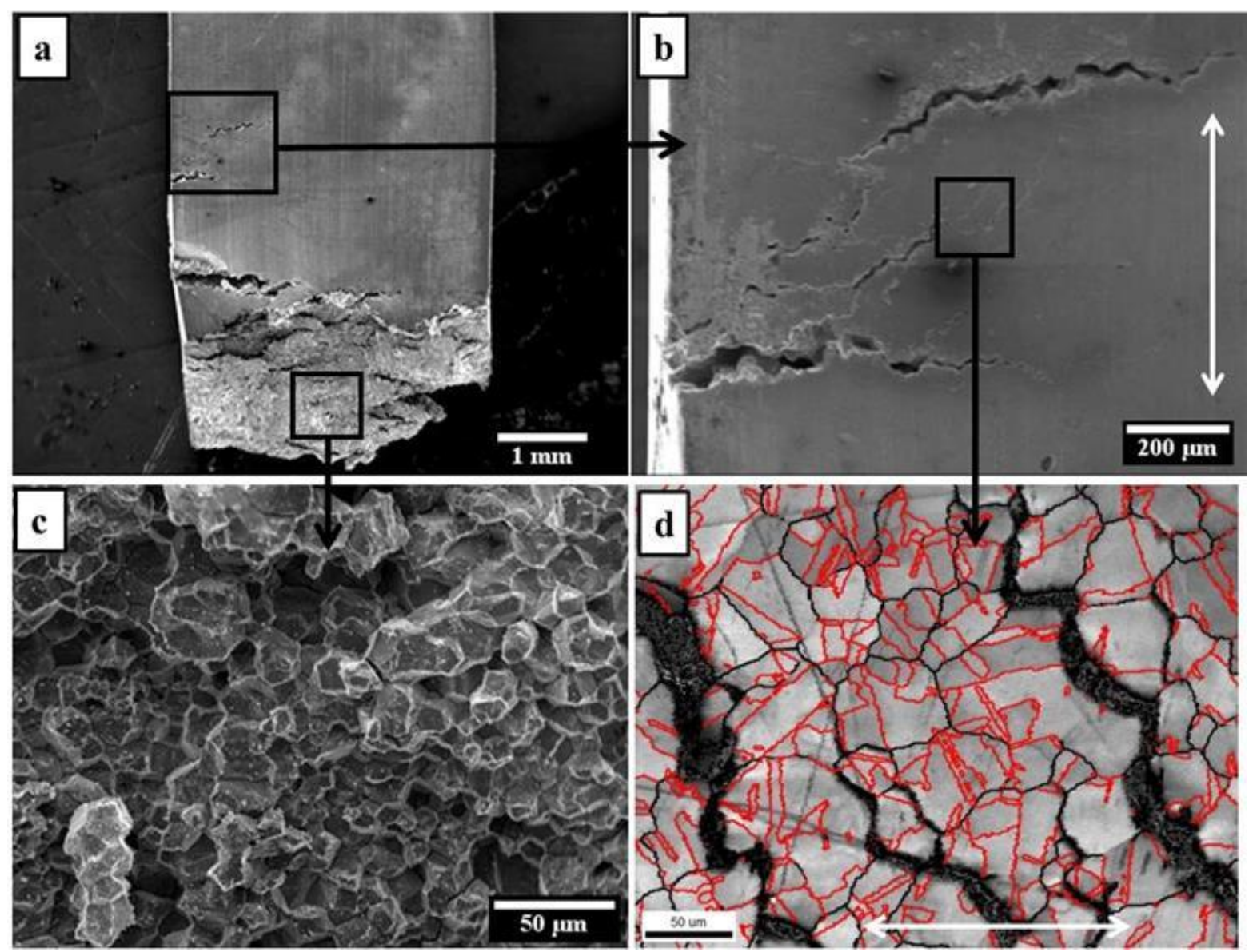

Figure 7. (a) SEM micrograph showing fracture surface and secondary cracking for SA condition after SSRT. (b) Micrograph showing secondary cracks in the gage section that were analyzed using EBSD. (c) High magnification micrograph of the fracture surface showing intergranular cracking. (d) Image quality EBSD map showing intergranular cracking overlaid with high angle boundaries in black and CSL boundaries in red. White arrow indicates the loading direction.

In case of SAGBE condition, a mixed mode of failure was observed as shown in Figure 8 $(a, b)$. Very few cracks were observed on the gage section and even these did not propagate the sample width or depth. A secondary crack, shown in Figure 8(c), that was analyzed in greater detail showed crack deflection at multiple locations. For instance, the crack was 
observed to have been arrested at a $\Sigma 3$ boundary. Note that the sample was strained to almost $30 \%$ and the kikuchi patterns degrade in locations of large strain especially near crack tips.
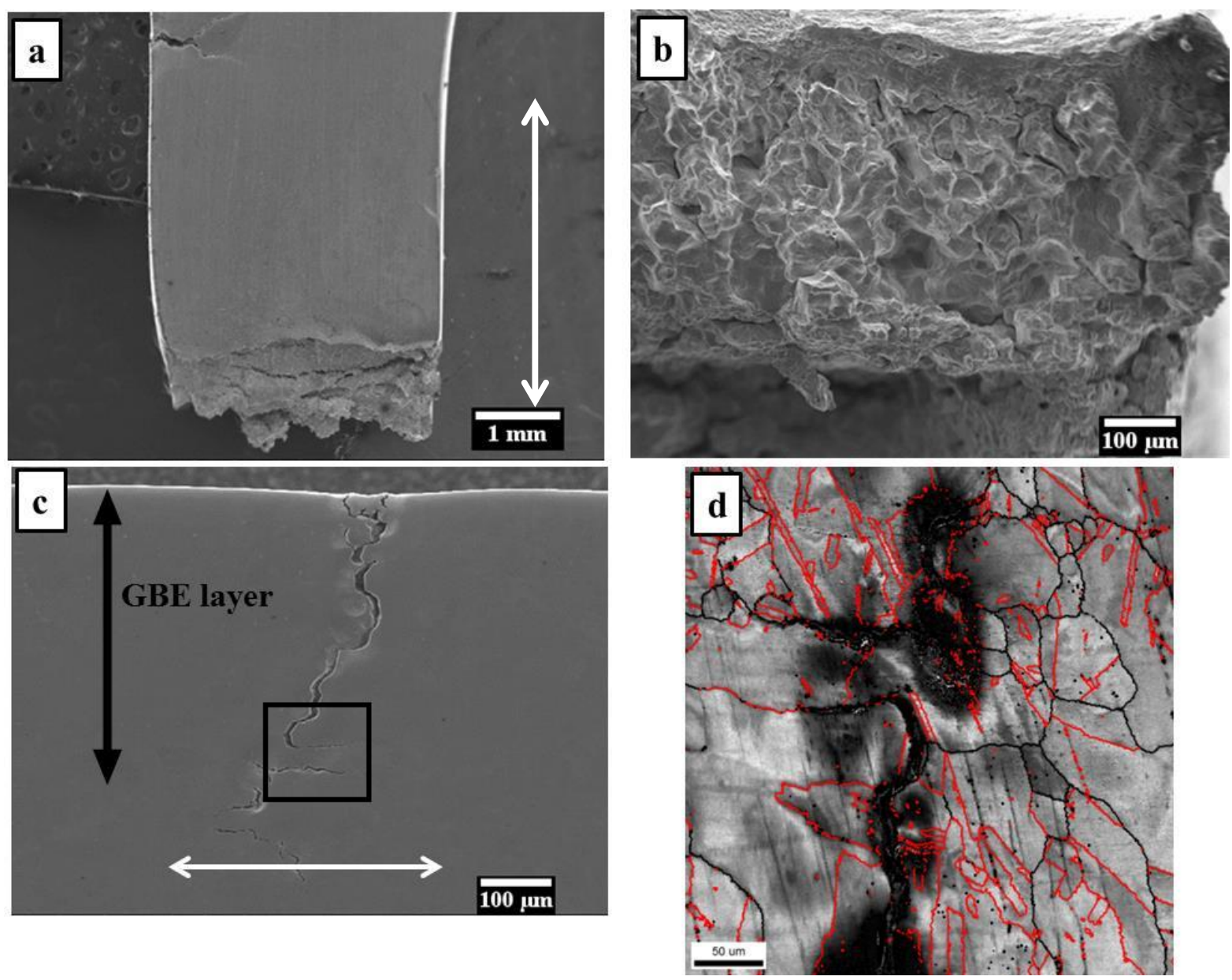

Figure 8. (a) SEM micrograph showing fracture surface and secondary cracking for SAGBE condition after SSRT. (b) High magnification micrographs of the fracture surface showing mixed mode of cracking. (c) Micrograph showing the location of a secondary crack that was analyzed in detail. (d) Image quality (IQ) map showing intergranular cracking overlaid with high angle boundaries in black and CSL boundaries in red. White arrow indicates the loading direction.

To analyze the interaction of SCC cracks with CSL boundaries in greater detail, we interrupted the SSRT test after nominal strain was $9 \%$ and the sample was held at this load/stress $( \pm 5 \mathrm{~N})$ for 24 hours or till failure. The SAGBE sample did not fail (test stopped after 24 hours) while the SA sample failed in less than 6 hours. 

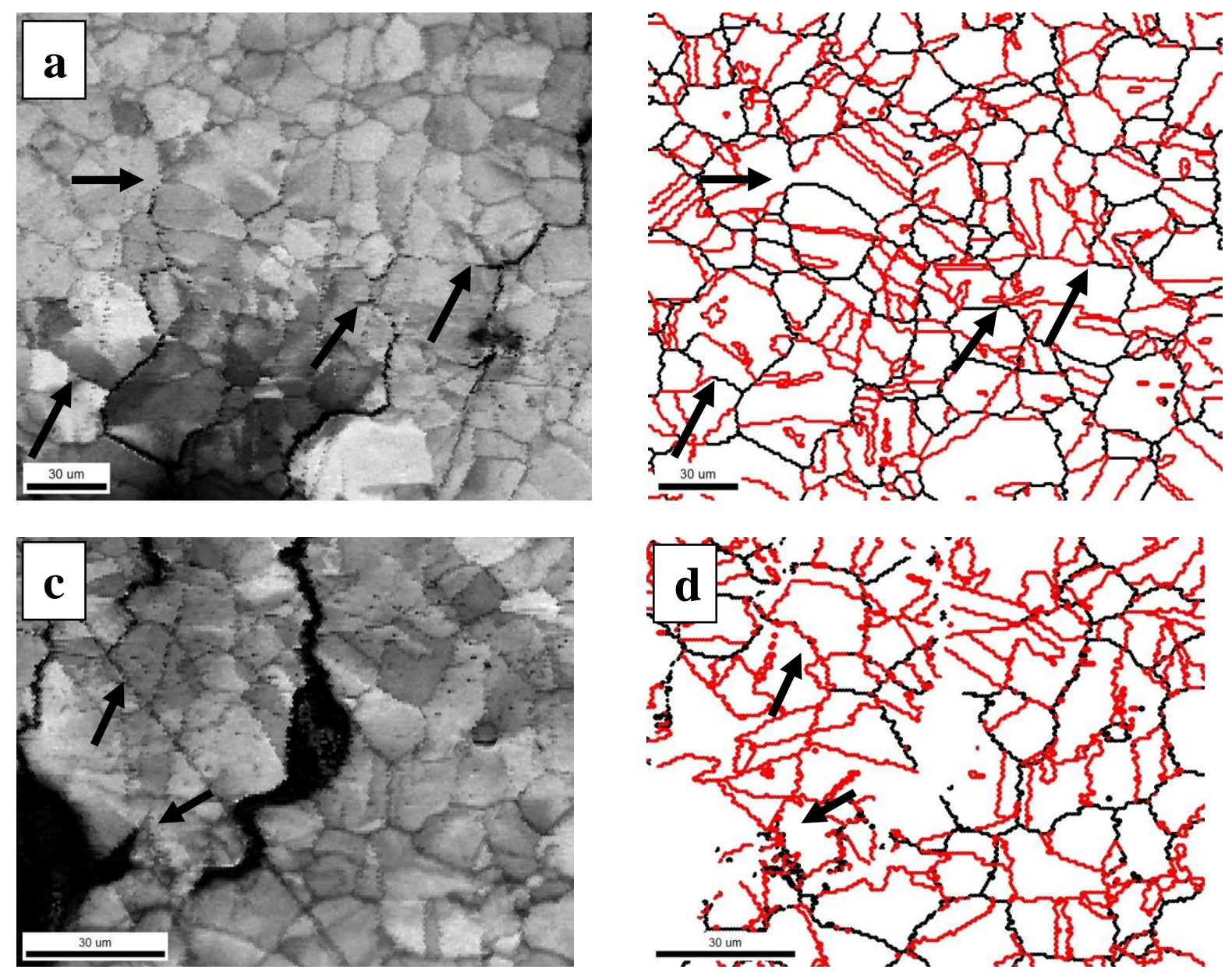

Figure 9. (a, c) IQ maps showing crack arrest locations (black arrows) in SAGBE sample. (b, d) Corresponding skeletonized orientation maps showing the character of grain boundaries. Random high angle grain boundaries are colored black while CSL boundaries are colored red. The direction of loading is horizontal.

In case of SAGBE sample, multiple instances of crack arrest were observed on the gage section after the test. Orientation maps were recorded from multiple locations around the cracks. IQ and corresponding grain boundary character maps presented in Figure $9(\mathrm{a}, \mathrm{c})$ and $(b, d)$ respectively show the character of grain boundaries ahead of the crack front. Cracks were observed to have been "arrested" on encountering a J2 type of triple junction. Several other instances where cracks were arrested or deflected from their path were observed in the SAGBE sample. In sharp contrast, the SA sample showed no instances of crack arrest or deflection as seen in Figure 10. More importantly, the cracks propagated the entire width of the sample and failed in 6 hours. 


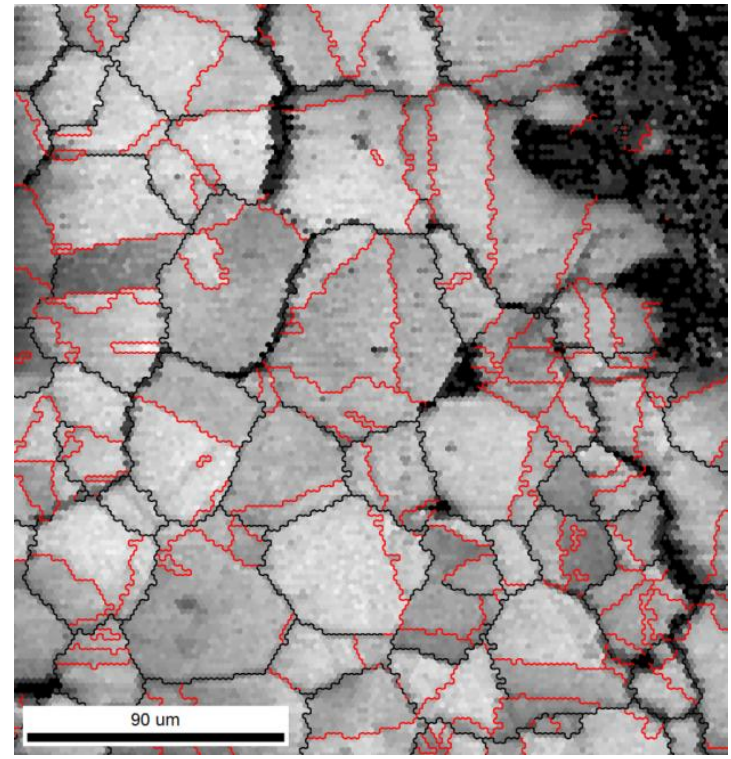

Figure 10. IQ map overlaid with grain boundaries from SA condition after the interrupted SSR test. Black lines denote random high angle boundaries while CSL boundaries are colored red.

\section{Discussion}

\subsection{Microstructure evolution}

Strain induced by UNSM was qualitatively measured by FWHM (shown in Figure 2) after the surface treatment. After 3 cycles of UNSM and subsequent annealing, the microstructure in the near surface region was significantly different as compared with the original microstructure. The network of random grain boundaries was observed to have broken down to smaller clusters after GBE. This disruption in random grain boundary networks has been reported after conventional thermo-mechanical processing routes in the literature [6,34]. The increase in CSL boundary fractions (by length) observed after SGBE in the near surface regions is similar to those reported after conventional single and multi-step thermo-mechanical processing. Also, the fracture characteristics are dependent on the distribution and interconnectivity of boundaries prone to crack propagation [16]. Therefore, changes to the triple junction distributions provide a direct co-relation to failure characteristics. In this study, we observed J2 and J3 fractions were significantly higher while 
the $\mathrm{J} 0$ fraction decreased after GBE in the near surface region. These characteristics are consistent with other observations of triple junction distribution after GBE [16,34,37].

The mechanism is likely to be similar to conventional GBE with the UNSM induced strain that decreases gradually from the near surface region to the interior. The multi-cycle treatment allows more possibilities for grain boundary migration and this further disrupts the random grain boundary network. Multiple interactions of twin boundaries (and its variants) with other random boundaries may introduce disruptions in the boundary network $[34,38,39]$. Though the strain induced by UNSM has not been quantified, residual stress and FWHM (Figure 2) provide a qualitative description of the strain in the near surface region. UNSM or other mechanical surface treatments can induce strain in regions to $\sim 250-500 \mu \mathrm{m}$ from the surface and thus could be used for near net shaped components or areas particularly prone to cracking. Alyousif et al. [40] reported a single step shot peening and annealing treatment to modify the microstructure in 304 stainless steel. They observed a decreasing gradient in twin fractions from the surface up to $100 \mu \mathrm{m}$. In this study, we used a multi-cycle approach to increase the CSL fractions and disrupt the random high angle grain boundary network to a depth of $250 \mu \mathrm{m}$.

\subsection{Effect of increased CSL fraction on corrosion behavior}

The decrease in DOS after GBE in austenitic stainless steels and Alloy 600 has been reported previously in a number of studies $[6,7,18,19,29]$. More significantly, this decrease in DOS has been attributed to increased fraction of twin boundaries and its variants. Additionally, CSL boundaries have been shown to be more resistant to precipitation of carbides and $\mathrm{Cr}$ depletion [18,41]. Jones and Randle [19] reported that $\Sigma 3(\sim 97 \%)$ and $\Sigma 9(\sim$ $80 \%$ ) were resistant to sensitization while $\Sigma 27$ and random high angle boundaries were attacked and not particularly resistant. A decrease in DOS by almost an order of magnitude 
suggests that the high CSL fraction as well as numerous disruptions in HAB network reduced Cr depletion indicated by the lower DOS.

We observed that that cracks were deflected or mitigated on encountering $\mathrm{J} 2$ type of triple junctions after surface GBE as shown in Figure 9. Similarly, improvements in high temperature fatigue [4] and hydrogen embrittlement [3] have been attributed to an increase in fractions of special boundaries particularly when the mode of failure is intergranular. Intergranular attack and stress corrosion cracks usually initiate at the surface and propagate to the interior along random grain boundaries. Though modification in grain boundary network is confined to $\sim 200-300 \mu \mathrm{m}$ in the near surface region, cracks would encounter more resistant CSL boundaries. Other studies show that $\Sigma 3$ boundaries are significantly more resistant to cracking than HAB $[10,38,42]$. While a few $\Sigma 3$ boundaries have been observed to crack and the "special" nature of $\Sigma 3^{\mathrm{n}}$ variants $(\mathrm{n}=2,3)$ with respect to their cracking resistance is under debate. Additionally, even some random HABs have been observed to "resistant" if they are unfavorably oriented to the applied stress direction $[38,43]$.

A few percolation models have been proposed to determine the probability for crack deflection or arrest when the crack encounters a resistant grain boundary [16,44-46]. Marrow et al.[45] observed cracks that were arrested by $\mathrm{J} 1$ and $\mathrm{J} 2$ type of triple junctions in sensitized 304 stainless steels after SCC tests in tetrathionate solutions at room temperature. Gertsman and Bruemmer[38] also observed cracks that were arrested at $\mathrm{J} 2$ type junctions and coherent $\Sigma 3$ boundaries were resistant to SCC. They also reported several $\Sigma 9$ and $\Sigma 27$ boundaries and $\Sigma 3$ boundaries with large deviations from ideal misorientation had cracked. The probability for crack arrest at a triple junction was calculated according to the 3 models proposed by Kumar et al. [39], Palumbo et al. [46] and Marrow et al. [45] and have been plotted in Figure 11. 
Palumbo et al. also proposed the following relation (Equation 8) to calculate the probability $(\mathrm{P})$ of crack arrest,

$$
P=\left(f_{s p}^{2}\right)+2\left[\left(f_{0}\right)\left(f_{s p}\right)\left(1-f_{s p}\right)\right]
$$

Where $f_{s p}$ is the fraction of special boundaries and $f_{0}$ is the fraction of interfaces in the distribution that are unfavorably oriented to the stress axis. This model relates the probability for crack arrest to the $f_{s p}$ but does not consider the spatial arrangement of these special boundaries in the microstructure.

It has been observed that fracture characteristics are primarily dependent on spatial distribution and interconnectivity of boundaries prone to crack propagation. To quantify the effect of improvement in the GBCD on the spatial connectivity of grain boundaries in two dimensions, triple junction distribution was evaluated [16]. Assuming J3 type of junctions to be non-entities in crack propagation, Kumar et al.[16] proposed (Equation 9) that the percolative paths in the microstructure would be broken if the following inequality/percolation ratio $\left(\mathrm{P}_{\mathrm{R}}\right)$ holds,

$$
P_{R}=\frac{J 2}{(1-J 3)} \geq 0.35
$$

Marrow et al.[45] observed cracks arrested at both J2 and J1 type of triple junctions and proposed the following (Equation 10),

$$
P=\frac{\left[f_{a} J 2+f_{b} J 1\right]}{(1-J 3)}
$$

where fa and fb (considered 1 and 0.5 respectively) are geometrical factors to account for unfavorably oriented sensitized boundaries at the triple junction. These three probabilistic models provide a basis to evaluate microstructures that are indicative of the resistance to SCC. 
The probability for crack arrest was observed to increase from 0.3 to about 0.5 after SGBE according to the model proposed by Marrow et al. and from 0.3 to 0.6 according to the model proposed by Palumbo et al. Similarly, $\mathrm{P}_{\mathrm{R}}$ was observed to increase from 0.03 to 0.18 as per the model proposed by Kumar et al. The decrease in SCC susceptibility can therefore be attributed to increase in the probability of crack arrest and percolation ratio calculated using the three models. It has been suggested that as the ratio of $\mathrm{J} 2 /(1-\mathrm{J} 3)$ is equal to or exceeds 0.35 , percolative paths in the microstructure will be broken [16]. Tsurekawa et al. also reported higher resistance to percolative intergranular corrosion in SS304L for microstructures with higher $\mathrm{P}_{\mathrm{R}}$ [47]. They also found that triple junction distribution fraction was a more important parameter to rank than maximum random boundary cluster length or GBCD. In this study, surface GBE increased the ratio $\left(\mathrm{P}_{\mathrm{R}}\right)$ by five times that in the baseline microstructure and this reduced the SCC susceptibility significantly. This further demonstrates that surface GBE increased the resistance to SCC in Alloy 600 in tetrathionate solutions. Since only $\Sigma 3, \Sigma 9$ and $\Sigma 27$ CSL boundaries have been considered for triple junction analysis, this type of analysis is a more conservative approach to evaluate the relative resistance of microstructure to SCC.

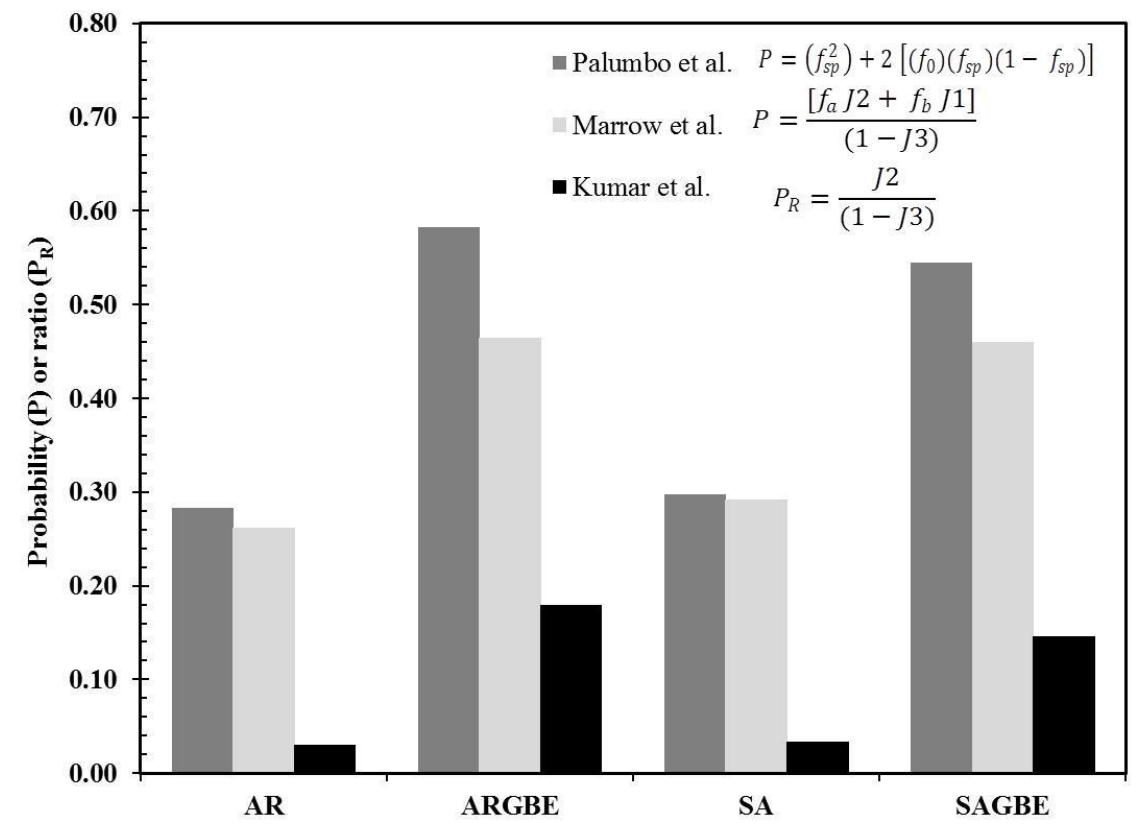


Figure 11. Probability for crack arrest as proposed by Palumbo et al. [46] and Marrow et al. [45] and percolation ratio, $\mathbf{P}_{\mathbf{R}}$ by Kumar et al. [16], for all conditions. Only $\Sigma$ 3, 9 and 27 CSL boundaries have been considered in the triple junction analysis.

\section{Conclusions}

The following conclusions can be drawn from this study,

1. The fraction of special boundaries was increased in the $200-300 \mu \mathrm{m}$ layer underneath the surface after iterative steps of ultrasonic peening (inducing high strain in the near surface region) and high temperature annealing.

2. The increase in fraction of low CSL boundaries, J1, J2 and J3 type of triple junctions and corresponding decrease in J0 type was similar to that observed in single or multistep conventional GBE processing schemes.

3. Surface GBE decreased the degree of sensitization significantly (an order of magnitude) and a SSRT results show an increase in elongation to failure and decrease in SCC susceptibility.

4. Detailed analysis of cracks on the gage section after SSR tests show cracks being deflected or mitigated at $\mathbf{J} 2$ type to triple junctions. Thus increase in fraction of special grain boundaries may have a dual effect of decreasing $\mathrm{Cr}$ depletion and mitigating intergranular cracks.

5. Calculations using percolative models showed that SGBE increased the probability for crack arrest and ratio $\left(\mathrm{P}_{\mathrm{R}}\right)$.

\section{Acknowledgements}

The authors are grateful for financial support of this research by the Nuclear Energy University Program (NEUP) of the US Department of Energy contract \#102835 issued under prime contract DE-AC07-05ID14517 to Battelle Energy Alliance, LLC. We also gratefully acknowledge the contribution of the State of Ohio, Department of Development and Third Frontier Commission, which provided funding in support of "Ohio Center for Laser Shock 
Processing for Advanced Materials and Devices"' and the equipment in the Center that was used in this work. MK was supported by the U.S. Department of Energy (DOE), Office of Basic Energy Sciences, Division of Materials Science and Engineering under FWP\# SCW0939. This work was partly performed under the auspices of the U.S. Department of Energy by Lawrence Livermore National Laboratory under Contract DE-AC52-07NA27344. Any opinions, findings, conclusions, or recommendations expressed in these documents are those of the author(s) and do not necessarily reflect the views of the DOE and the State of Ohio, Department of Development.

\section{References}

[1] B. Alexandreanu, B.H. Sencer, V. Thaveeprungsriporn, G.S. Was, Acta Mater. 51 (2003) 3831-3848.

[2] E.M. Lehockey, G. Palumbo, P. Lin, A.M. Brennenstuhl, 36 (1997) 1211-1218.

[3] S. Bechtle, M. Kumar, B.P. Somerday, M.E. Launey, R.O. Ritchie, Acta Mater. 57 (2009) 4148-4157.

[4] Y. Gao, M. Kumar, R.K. Nalla, R.O. Ritchie, Metall. Mater. Trans. A 36 (2005) 33253333.

[5] S. Kobayashi, M. Nakamura, S. Tsurekawa, T. Watanabe, J. Mater. Sci. 46 (2011) 4254-4260.

[6] M. Shimada, H. Kokawa, Z.. Wang, Y. Sato, I. Karibe, Acta Mater. 50 (2002) 23312341.

[7] S.K. B., B.S. Prasad, V. Kain, J. Reddy, Corros. Sci. 70 (2013) 55-61.

[8] L. Tan, X. Ren, K. Sridharan, T.R. Allen, Corros. Sci. 50 (2008) 3056-3062.

[9] C. Cheung, U. Erb, G. Palumbo, Mater. Sci. Eng. A 185 (1994) 39-43.

[10] B. Alexandreanu, B. Capell, G.S. Was, Mater. Sci. Eng. A 300 (2001) 94-104.

[11] D.C. Crawford, G.S. Was, 23 (1992).

[12] G. Palumbo, K.T. Aust, E.M. Lehockey, U. Erb, P. Lin, Scr. Mater. 38 (1998) 16851690.

[13] Y. Pan, B.L. Adams, T. Olson, N. Panayotou, Acta Mater. 44 (1996) 4685-4695. 
[14] A. King, G. Johnson, D. Engelberg, W. Ludwig, J. Marrow, Science (80-. ). 321 (2008) 382-386.

[15] V. Randle, M. Coleman, Acta Mater. 57 (2009) 3410-3421.

[16] M. Kumar, W.E. King, A.J. Schwartz, Acta Mater. 48 (2000) 2081-2091.

[17] Q. Li, B.M. Guyot, N.L. Richards, Mater. Sci. Eng. A 458 (2007) 58-66.

[18] H. Yun Bi, H. Kokawa, Z. Jie Wang, M. Shimada, Y.S. Sato, Scr. Mater. 49 (2003) 219-223.

[19] R. Jones, V. Randle, Mater. Sci. Eng. A 527 (2010) 4275-4280.

[20] G.S. Was, V.B. Rajan, Corrosion 43 (1987) 576-579.

[21] R. Bandy, R. Roberge, R. Newman, Corros. Sci. 23 (1983) 995-1006.

[22] R. Newman, K. Sieradzki, H. Isaacs, Metall. Trans. A 13 (1982) 2015-2026.

[23] S.M. Bruemmer, G.S. Was, J. Nucl. Mater. 216 (1994) 348-363.

[24] M. Tsai, W. Tsai, J. Lee, Corros. Sci. 34 (1993) 741-757.

[25] A. Telang, A.S. Gill, S. Teysseyre, S.R. Mannava, D. Qian, V.K. Vasudevan, Corros. Sci. 90 (2015) 434-444.

[26] C. Ye, A. Telang, A.S. Gill, S. Suslov, Y. Idell, K. Zweiacker, J.M.K. Wiezorek, Z. Zhou, D. Qian, S. Ramaiah Mannava, V.K. Vasudevan, Mater. Sci. Eng. A 613 (2014) 274-288.

[27] C.-M. Suh, G.-H. Song, M.-S. Suh, Y.-S. Pyoun, Mater. Sci. Eng. A 443 (2007) 101106.

[28] D.G. Brandon, Acta Metall. 14 (1966) 1479-1484.

[29] P.M. Ahmedabadi, V. Kain, B.K. Dangi, I. Samajdar, Corros. Sci. 66 (2013) 242-255.

[30] ASTM E112-13, Standard Test Methods for Determining Average Grain Size, ASTM International, West Conshohocken, PA, 2013.

[31] A. Gill, A. Telang, S.R. Mannava, D. Qian, Y.-S. Pyoun, H. Soyama, V.K. Vasudevan, Mater. Sci. Eng. A (2013).

[32] V. Randle, M. Coleman, M. Waterton, Metall. Mater. Trans. A 42 (2010) 582-586.

[33] V. Randle, G. Owen, Acta Mater. 54 (2006) 1777-1783.

[34] C.A. Schuh, M. Kumar, W.E. King, Acta Mater. 51 (2003) 687-700. 
[35] J. Kai, C. Tsai, T. Huang, M. Liu, Metall. Trans. A 20 (1989) 1077-1088.

[36] S. Abe, M. Kojima, Y. Hosoi, in Stress Corrosion Cracking Susceptibility Index, ISCC, of Austenitic Stainless Steels in Constant Strain-Rate Test (STP 665), STP 665 Stress Corrosion Cracking - The Slow Strain-Rate Technique (ASTM International):, 1979, pp. 294-304.

[37] P. Fortier, W. a. Miller, K.T. Aust, Acta Mater. 45 (1997) 3459-3467.

[38] V.Y. Gertsman, S.M. Bruemmer, Acta Mater. 49 (2001) 1589-1598.

[39] M. Kumar, A.J. Schwartz, W.E. King, Acta Mater. 50 (2002) 2599-2612.

[40] O.M. Alyousif, D.L. Engelberg, T.J. Marrow, J. Mater. Sci. 43 (2007) 1270-1277.

[41] E.. Trillo, L.E. Murr, J. Mater. Sci. 33 (1998) 1263-1271.

[42] S. Rahimi, D.L. Engelberg, J. a Duff, T.J. Marrow, J. Microsc. 233 (2009) 423-31.

[43] T.J. Marrow, L. Babout, A.P. Jivkov, P. Wood, D. Engelberg, N. Stevens, P.J. Withers, R.C. Newman, J. Nucl. Mater. 352 (2006) 62-74.

[44] C. A. Schuh, M. Kumar, W.E. King, Acta Mater. 51 (2003) 687-700.

[45] T.J. Marrow, L. Babout, A. P. Jivkov, P. Wood, D. Engelberg, N. Stevens, P.J. Withers, R.C. Newman, J. Nucl. Mater. 352 (2006) 62-74.

[46] G. Palumbo, P.J. King, K.T. Aust, U. Erb, P.C. Lichtenberger, Scr. Metall. Mater. 25 (1991) 1775-1780.

[47] S. Tsurekawa, S. Nakamichi, T. Watanabe, Acta Mater. 54 (2006) 3617-3626. 